XV. Description of a New Species of Macropus from New Hol-land. By Aylmer Bourke Lambert, Esq.F.R.S. V.P.L.S.

Read April 16, 1805.

Macropus elegans.

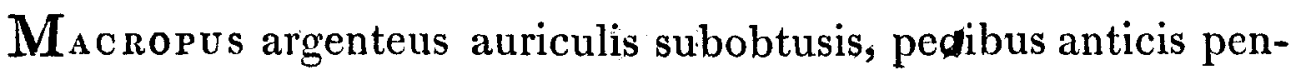
tadactylis.

\title{
TAB. XVI.
}

The account of this animal, and the drawing which $I$ here offer to the Society, were taken from a living specimen lately brought from New South Wales, and now in the possession of Mr. Pidcock of Exeter 'Change. It is distinguished by the Settlers in that country, by the name of the Silver or Brush Kangaroo, and by the Natives is called Ba-ga-ree. It appears to be a very distinct species from the first discovered one, which Dr. Shaw in his General Zoology* has named Macropus major, differing from that, not only in colour, but also in being much smaller, and of a more handsome shape. The colour is a beautiful silver-gray; and, upon the whole, it is one of the most elegant animals $I$ ever saw. It is also very docile.

Dr. White, who so long resided in New South Wales, informs me that this species is very scarce, and that its habits are very different from those of the common Kangaroo, it being always

\footnotetext{
* Shaw's General Zoology, vol, i. p. 505.
} 


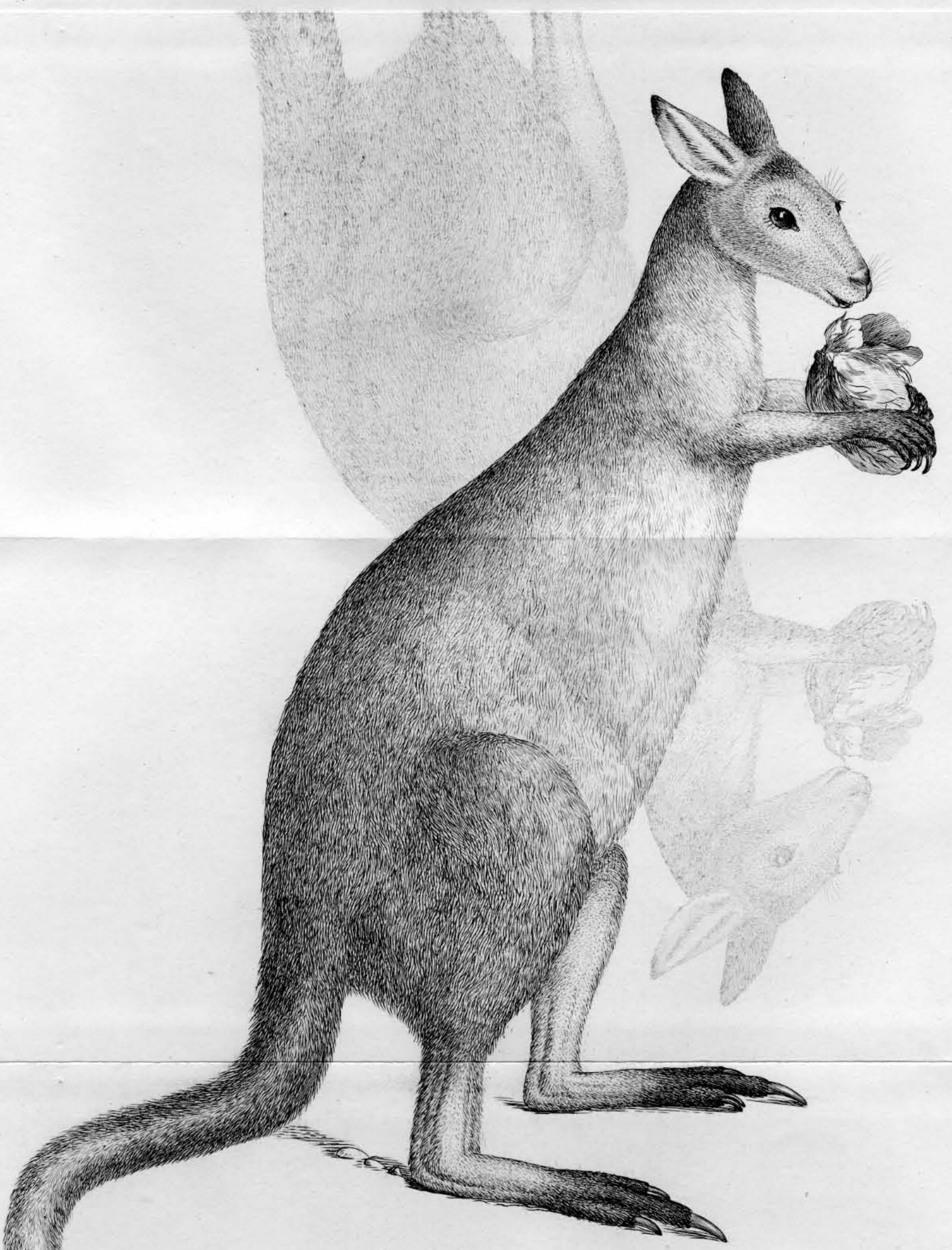


Mr. Lamiert's Description of a New Species of Macropus. 319

found solitary, whereas the other is found in herds of forty or fifty together. Among the numerous Drawings of Natural History which Dr. White brought home from that country, and are now in my possession, this animal is wanting, owing, no doubt, to the difficulty of procuring a specimen.

The measurement of the animal above described, is as fol lows :

Inches.

Length from the tip of the nose to the end of the tat $62 \frac{z}{10}$

From the tip of the nose to the eye - - $\quad 2 \frac{8}{10}$

From the tip of the nose to the back part of the skull $55^{\frac{7}{0}}$

From the back part of the skull to the tip of the tail 57

Length of the tail $\quad-\quad-\quad-\quad-\quad-26 \frac{2}{10}$

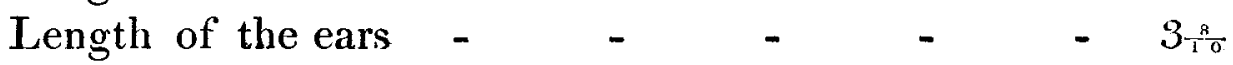

From the tip of the fore claw to the top of the shoulder $122^{\frac{6}{6}}$

Length of the fore leg from the claw to the knee - 8

From the tip of the hind claw to the top of the thigh 24

Length of the hind leg from the claw to the knee 10

Girth at the widest part, three inches before the hind

$\begin{array}{lllllllll}\text { legs } & - & - & - & - & - & - & 28\end{array}$

Girth three inches behind the fore legs $\quad-\quad-\quad 19$

XVI. $E r-$ 